\title{
How Does Mimulus verbenaceus (Phrymaceae) Set Seed in the Absence of Pollinators?
}

\author{
Robert K. Vickery, Jr.
}

Received: 24 April 2008/Accepted: 25 June 2008/Published online: 19 August 2008

(C) The Author(s) 2008

\begin{abstract}
Mimulus verbenaceus has successfully invaded and/or competed for the very specialized habitats of desert seeps and springs characterized by scarce or no pollinators (personal observation). It has done so by evolving an ingenious mechanism of reproductive assurance in which the senescing epipetalous corolla bends down, abscisses and slides down its style dragging its anthers over the stigma lobes, resulting in self-pollination. This dragging mechanism both depends on the plants ability to self-pollinate and presumably promotes the evolution of selfpollination by providing an advantage-invasion of new habitats-to counter-balance the disadvantages of selfing. M. verbenaceus has evolved a second means of reproductive assurance that depends on the nearness of the anthers to the stigma lobes. They are close, even touching, in the red flowers, leading to much self-pollination and are well separated in the yellow flowers leading to little self-pollination. This advantage of the red-flowered plants likely explains the relative abundance of the red morph and the rarity of the yellow morph in nature as well as the greater seed set of the red-flowered morph than that of the yellowflowered morph.
\end{abstract}

Keywords Architecture of the flower - Dragging . Grand Canyon - Mimulus verbenaceus · Phrymaceae . Plantaginaceae $\cdot$ Reproductive assurance .

Scrophulariaceae $\cdot$ Self-pollination

R. K. Vickery, Jr. ( $₫)$

Department of Biology, University of Utah, 257 South 1400

East, Salt Lake City, UT 84112, USA

e-mail: zundel@biology.utah.edu

\section{Introduction}

A fascinating chapter in evolution is the co-evolution of flowering plants and animals, particularly insects. The animals get food-nectar and pollen. The flowers get pollinator service leading to seed set and reproduction. For example, the red-flowered monkey flowers of section Erythranthe of the genus Mimulus are pollinated by bees and hummingbirds. However, Mimulus verbenaceus of that section occurs in remote, isolated springs and seeps in the deserts of southwestern United States and northwestern Mexico where there are few, if any pollinators. I repeatedly observed monkey flower populations in 7 such habitats and observed no pollinators at all. How do these populations persist in the absence or scarcity of pollinators? What are their means of reproductive assurance to achieve seed set?

Studies of reproductive assurance mechanisms are burgeoning, with a growing array of mechanisms described and a widening range of plants studied. Interesting examples include corolla abscission and stigmatic curling in Mimulus (Dole 1990, 1992), cleistogamy in Viola (Culley 2002), staminal growth in Crotolaria (Etcheverry 2001) and Collinsia (Armbruster et al. 2002), wind in Salix (Karrenberg et al. 2002) and Pinus (Squilace and Goddard 1982), and reliance on clonal growth in Thalictrum (Steven and Waller 2004) and Opuntia (Palleiro et al. 2006). See Fenster and Martén-Rodríguez (2007) for a current, extensive summary of plant reproductive assurance mechanisms and species. These different means of achieving reproduction are often vital to the survival of their species in habitats with few, if any, pollinators, and these in unpredictable supply (Baker 1959). Most of the various mechanisms of reproductive assurance depend on their species having evolved the ability to self-pollinate. Perhaps their ability to invade new habitats and/or compete in old 
ones in which pollinators are scarce not only depends on, but also facilitates the evolution of selfing. It provides a counter-balancing advantage, the ability to invade habitats with few, if any pollinators to offset the disadvantages of selfing such as inbreeding depression and seed discounting (Herlihy and Eckert 2002).

Of the scores of species studied for reproductive assurance several belong to the genus Mimulus-M. ringens $\mathrm{L}$. (Mitchell et al. 2004) of section Eumimulus and three members of the M. guttatus DC. complex of section Simiolus (Dole 1992). Another Monkey Flower species, M. verbenaceus Greene, of the M. cardinalis complex of the related, but strikingly distinctive section Erythranthe (Vickery 1978) seems a likely candidate for studying reproductive assurance. It is self-fertile, sets seeds in nature, and sets numerous seeds in our pollinator-free greenhouses. Further, I have observed-in apparent explanation of its seed set-that the senescing epipetalous corollas bend down, absciss and slide down their pistils dragging their anthers over the stigma lobes potentially resulting in self-pollination which Dole $(1990,1992)$ described as dragging in his studies of contrasting Mimulus guttatus.

In M. verbenaceus, would enough pollen and ovules still be viable and functional in senescing flowers to produce seeds? If so, would the putative explanation lead to seed set in the absence of pollinators? Conversely, would blocking the putative mechanism of self-pollination result in sterility? What other factors, e.g., architecture of the flowers, parthenogenesis, cleistogamy, stigmatic curling, wind, etc. might contribute to seed set in the absence of pollinators?

\section{Materials and Methods}

\section{Plant Material}

Mimulus verbenaceus Greene belongs to section Erythranthe of the genus Mimulus, family Phrymaceae (Beardsley and Olmstead 2002) or more recently family Plantaginaceae (Judd et al. 2008) formerly of the more familiar family Scrophulariaceae. This relatively uncommon, water-loving species occurs in the southwestern United States and northwestern Mexico, including remote desert seeps and springs (Abbey 1971). The plants are perennial by creeping root stocks. The stems are usually upright and as much as $50 \mathrm{~cm}$ tall, but sometimes hanging. The corollas are tubular, showy, $3-5 \mathrm{~cm}$ long, usually cardinal red, but rarely bright yellow. Red flower color is due to a visual blend of six different pink to lavender anthocyanins and a yellow carotene (Vickery 1978). Yellow flower color is due to the action of a pair of recessive genes that block the production of the anthocyanins thereby revealing the yellow carotene.
The upper two corolla lobes are strongly reflexed and the lower three are spreading. The four stamens are epipetalous. The anthers are hirsute. The pollen is powdery, ca. $36 \mu \mathrm{m}$ in diameter, that is, of average size (Erdtman 1969). The single pistil exceeds the anthers and corolla (Fig. 1). The stigma is bi-lobed. The lobes are finely pabescent. They are sensitive but usually will re-open in 30 $60 \mathrm{~min}$ following stimulation or pollination. Based on numerous observations and measurements, I found that the anthers are held close (1 $\mathrm{mm}$ or less) to the stigma lobes in the red flowered morph, whereas in the yellow morph they are clearly separated (4-5 $\mathrm{mm}$ or more) from the stigma lobes (Fig. 1). The distance between the anthers and stigma lobes appears to be controlled by one or more pairs of quantitative genes that control the length of the staminal filaments. If the filaments are long then the separation is $1 \mathrm{~mm}$ or less. If short, the separation is $4-5 \mathrm{~mm}$. This locus (or loci) appears to be closely linked to the locus

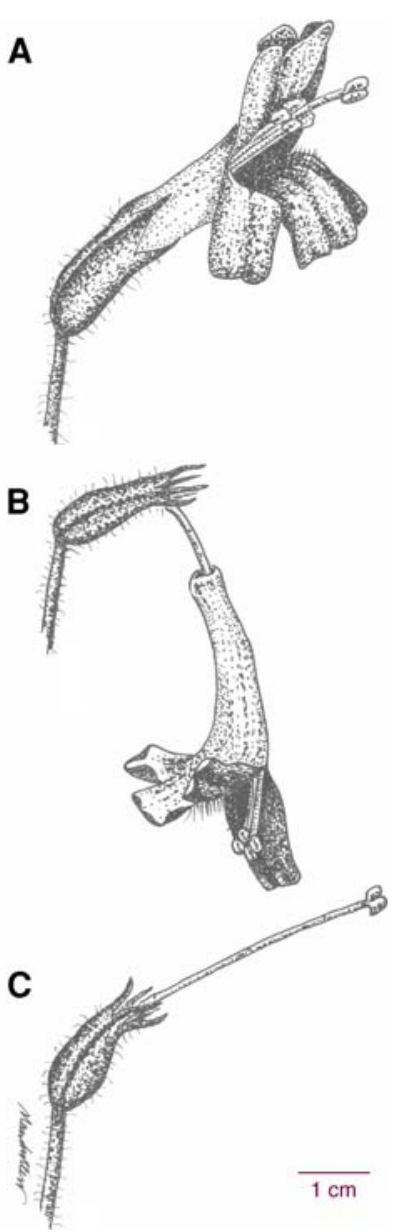

Fig. 1 (a) Mimulus verbenaceus flower. Note the bi-lobed stigma well separated from the four anthers-typical of the yellow flowers. (b) Senescing $M$. verbenaceus flower. Note the epipetalous stamens sliding with the corolla down the pistil. (c) Senescent flower-Note the stigma lobes have re-opened, the corolla and its attached stamens have slipped off, and the pistil has returned to an upright position 
controlling the production of the anthocyanins, that is, to flower color. So, yellow flowers have $4-5 \mathrm{~mm}$ separation of the anthers from the stigma lobes. Red flowers have $1 \mathrm{~mm}$ or less separation. The $\mathrm{F}_{1}$ hybrids of red $\mathrm{x}$ yellow proved to be red-flowered with intermediate separation of $3 \mathrm{~mm}$ between the anthers and stigma lobes (experiments in progress).

Both color morphs went from anthesis to senescence in 34 days in the greenhouse and in the experimental garden. Both morphs set abundant seeds. Both have $n=8$ chromosomes (Vickery and Miller 2007) and are fully inter-fertile (experiments in progress). For more information on $M$. verbenaceus see Adele Grant's (1924) monograph of the genus Mimulus, as well as Hiesey et al. (1971), Vickery (1978), Vickery and Wullstein (1987), Thompson (1993), Schemske and Bradshaw (1999) and Beardsley et al. (2003).

The plants used in these studies were grown from transplants and seeds from a wild population growing in and below a "hanging garden" seep high on the sandstone cliffs of remote Vassey's Paradise (Appendix 1) at the mouth of South Canyon below Lee's Ferry in the Grand Canyon-elevation $985 \mathrm{~m}$ (ca. 3,200'), latitude $36^{\circ} 39^{\prime} \mathrm{N}$, longitude $111^{\circ} 51^{\prime} 30^{\prime \prime} \mathrm{W}$ (Arizona, Coconino County 1985). This population was selected because it is one of the very few that contain the yellow flower color morph as well as the usual red flower color morph. Both morphs set seeds in nature. However, there were too few ripe capsules at the times these difficult collections were made to permit estimates of their seed sets in nature. I thought it would be highly instructive to carefully compare these two color morphs. Would the same mechanisms lead to seed set in the absence of pollinators?

These cultures have my numbers 14,088 for the red morph and 14,089 for the yellow morph. Specimens are in the Garrett Herbarium (UT) of the University of Utah (Appendix 1).

\section{Methods}

Plants were grown in the pollinator-free greenhouses of the Biology Department, University of Utah except for one population which was grown in a pollinator-free screen cage in the experimental garden. When an experiment required it, the plants were bottom-watered so as to avoid sprinkling moving the pollen, and shielded so as to avoid the wind from the greenhouse fans pollinating the flowers. Of the 40, often more, plants used in each experiment, half of the plants had red flowers and half yellow flowers.

To verify that $M$. verbenaceus was self-fertile and sets seeds in the absence of pollinators, I grew a large population in a pollinator-free greenhouse and checked its overall fertility as well as that of both the red and the yellow flower color morphs.
In order to ascertain whether "old" pollen and "old" ovules-in the sense of their age at the time of senescence-were viable and functional, I tried several hybridizations in my main pollinator-free greenhouse. A mix of "old" pollen was collected from anthers of both red and yellow corollas that were in the process of sliding down their pistils and applied to stigmas of red and yellow flowers in recently opened, emasculated flowers. Reciprocally, a mix of ripe pollen from recently opened flowers was gathered and applied to stigmas exposed by the sliding corollas in flowers that had been emasculated when first opened, i.e., to "old" ovules. Also, and most critically, "old" pollen was used to fertilize "old" ovules in previously emasculated flowers. As a control, "young" pollen was applied to "young" ovules.

To test whether, in the absence of pollinators, the putative reproductive assurance mechanism worked. I made use of the trait of $M$. verbenaceus flowers being borne in pairs. One member of each pair was left unmanipulated whereas the corolla of the other member of the pair was glued (Elmer's glue, Elmer's Products, Inc., Columbus $\mathrm{OH} 43215$ ) to its calyx which prevented the dragging mechanism of self-pollination from occurring. For comparison with these indoor tests in our pollinatorfree greenhouses, I tested a population in a pollinator-free screen cage outdoors in the experimental garden in as much as it was not feasible to test the wild population at Vassey's Paradise.

Additional possible means of seed set were examined also. Specifically, did the architecture of the flowers, or parthenogenesis, or cleistogamy, or stigmatic curling, or wind pollination, etc., explain the seed set in flowers that set seeds over and above those explained by dragging?

To test for whether the architecture of the flower, specifically, the distance of separation of the anthers from the stigma lobes could contribute to reproductive assurance, I made use of the convenient characteristic that the yellow flowers had a clear 4-5 mm or more separation (Fig. 1) whereas the red flowers had $1 \mathrm{~mm}$ or less, even zero, separation. Populations of red flower color morphs and of yellow flower color morphs were grown in a polyethelene wind exclosure in my main pollinator-free greenhouse. The corollas were glued to the calyces to prevent seed set due to dragging.

To test for parthenogenesis, I emasculated the flowers of four large populations prior to anthesis and allowed the capsules to mature seeds. To check for cleistogamy I carefully observed many flower buds in the course of carrying out the above experiments to determine whether the buds all opened or if some remained closed (cleistogamous). To check for stigmatic curling, I observed flowers that ranged from freshly opened to senescent to ascertain whether one or both stigma lobes would curl towards the anthers with age. 
To test for possible wind pollination, that is, pollination due to wind borne pollen from other flowers of that plant or from other plants of that population, I grew a large experimental population in our main pollinator free greenhouse. Half the plants of the population were subjected daily to $2 \mathrm{~h}$ of 3 km.p.h. (ca. 2 m.p.h.) wind from an oscillating fan, i.e., $6 \mathrm{~km}$ (ca. 4 miles) of wind per $24 \mathrm{~h}$. This amount of wind is approximately $1 / 10$ the mean $60 \pm 16 \mathrm{~km}$ (ca $38 \pm 10$ miles) of wind per day recorded at the Grand Canyon during the flowering season of MayAugust during 1988-1997 (Weather Bureau 1988-1997). The reduction is to take into account the estimated amount of sheltering from the wind experienced by the $M$. verbenaceus plants in their protected seep. This amount of wind was enough to provide the swirling air currents optimal for wind pollination involving medium sized, powdery pollen grains (Niklas 1985). Control plants, the other half of the experimental population, were shielded from the wind by a polyvinyl plastic exclosure. In both the experimental and control portions of the population, the corollas were glued to the calyces to avoid selfing due to dragging.

To test for wind-induced self-pollination, I selected plants that each had a large bud that would soon open, but in which anthesis had not yet occurred. Other buds and flowers were removed from each test plant to avoid geitonogamy. Each plant was placed in a separate, pollinatorfree greenhouse in which there were no other Mimulus plants. They were exposed to wind as above. After 3 days their stigmas and anthers were removed to avoid any further accidental pollination. The plants were then returned to my main greenhouse. I tested 5 plants at a time (limited by the number of available greenhouses). For the control with no wind I was able to test 12 plants at a time.

Approximately a month after anthesis in each of the experiments just described, ripe capsules were harvested. Seeds were counted with the aid of a low magnification lens.

For each population, the statistical summary program of the Microsoft Excel 98 computer program (1998) was used to verify the sample size $(n)$ and to compute the means and standard errors. For each simple pairwise comparison of an experimental population and its control, red-flowered plants' results and yellow-flowered plants' results, etc. the analysis of variance program of the Microsoft Excel 98 computer program was used to compute the F-statistic and its $P$-value.

\section{Results}

Mimulus verbenaceus is self-fertile and set abundant seeds in the greenhouse in the absence of pollinators. It averaged 813 seeds per capsule overall with a standard error of \pm 36
(Fig. 2). The red-flowered morph averaged $885 \pm 56$ seeds per capsule and the yellow-flowered morph averaged $752 \pm 46$ seeds per capsule. The difference is not significant $(F=3.7630, P=0.0545)$ so the determination of the underlying numbers of ovules and pollen grains did not seem so urgent and remains for a future study.

The average seed set in the absence of pollinators, $813 \pm 36$ seeds per capsule, is only slightly and not significantly $(F=1.0190, P=0.3140)$ below the $861 \pm 75$ seeds per capsule seed sets of the hand-pollinated young $\mathrm{x}$ young controls (Figs. 2and 3). The red-flowered morph of the young $x$ young controls averaged $984 \pm 106$ seeds per capsule which is not significantly $(F=1.7633, P=0.187)$ more than the yellow-flowered morph's average $785 \pm 106$ seeds per capsule.

The pollen ("old" pollen) and ovules ("old" ovules) of senescing flowers proved to be still viable and functional (Fig. 3). The cross using "old" pollen to pollinate "old" ovules set an average of $273 \pm 38$ seeds per capsule, very significantly $(F=55.2557, \quad P<0.0001)$ below the $861 \pm 75$ seeds per capsule of the "young" $x$ "young" control, but fully ample for fertility. In each of the four crosses, the red-flowered plants tended to set more seeds than the yellow-flowered plants, but significantly so $(F=11.8573, P<0.0001)$ only in the "old" $\mathrm{x}$ "old" cross.

Testing the putative dragging reproductive assurance mechanism of self-pollination revealed that it worked well (Fig. 4a, b). Of the 276 flowers (both red and yellow) tested, with normal dragging and no pollinators, 245 set seeds, for an average of $450 \pm 24$ seeds per capsule. However, when dragging was blocked in the other flower

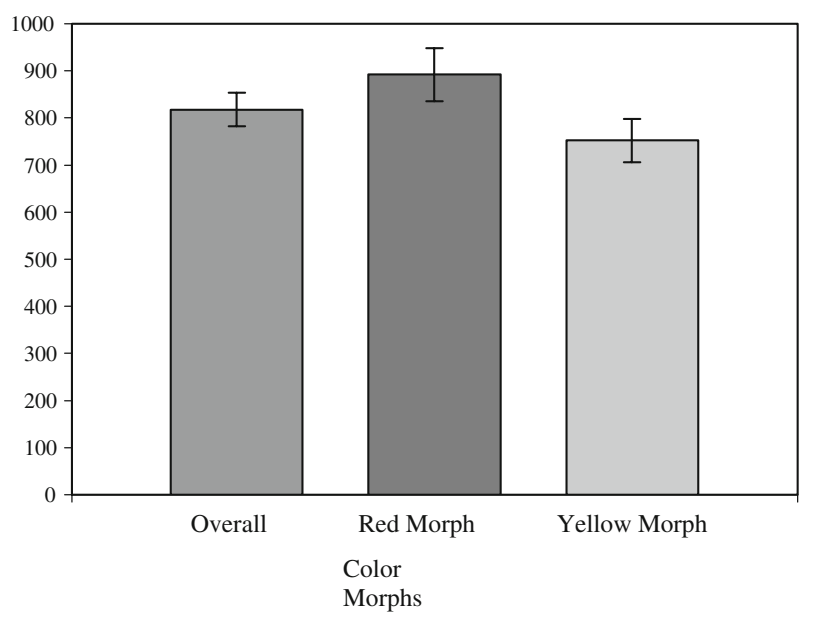

Fig. 2 Mean seed sets of M. verbenaceus in our pollinator-free greenhouse. (1) Overall seed set of a mixed population of red and yellow flower color morphs, 813 with a standard error of \pm 36 , $n=134$. (2) Seed set of red flower color morph, $885 \pm 56, n=62$. (3) Seed set of yellow flower color morph, $752 \pm 46, n=72$. The error bars equal \pm one standard error 


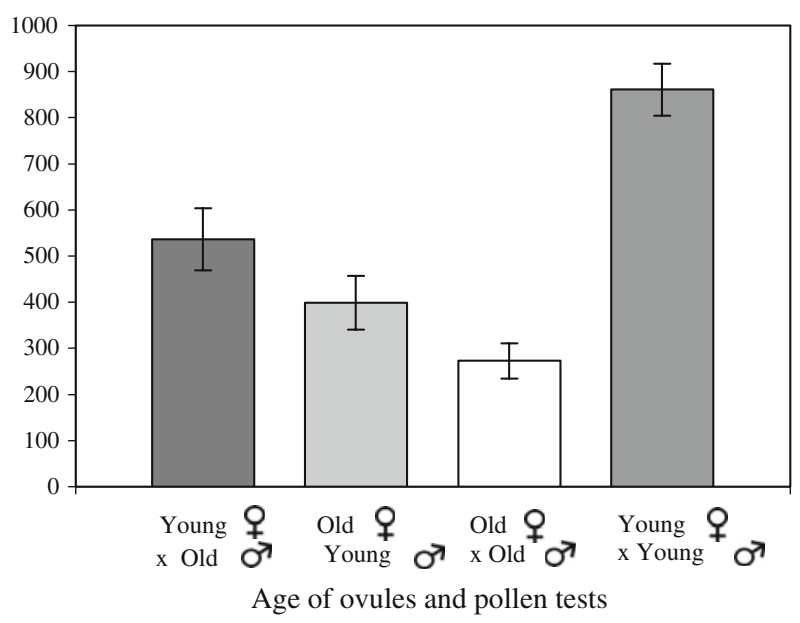

Fig. 3 Age of ovules and pollen experiments - mean seed sets per capsule of mixed populations of red and yellow flower color morphs. (1) "young ovules" x "old" pollen, $501 \pm 57, n=60$. (2) "old" ovules x "young" pollen, $402 \pm 57, n=63$. (3) "old" ovules $x$ "old" pollen, $273 \pm 38, n=71$. (4) "young" ovules x "young" pollen, $861 \pm 75, n=56$. The error bars equal \pm one standard error

of each pair, 130 of the 276 flowers set seeds anyhow for an overall average of $108 \pm 15$ seeds per capsule. With dragging but no pollinators the red flowers averaged $546 \pm 37$ seeds per capsule whereas the yellow flowers averaged a not significantly $(F=3.8179, P=0.0517)$ less $352 \pm 27$ seeds per capsule (Fig. 4b). With dragging blocked the red flowers averaged $139 \pm 24$ seeds per capsule whereas the yellow flowers averaged a not significantly $(F=3.755, P=0.0538)$ less $76 \pm 16$ seeds per capsule (Fig. 4b).

The population in the pollinator-free screen cage produced over 100 flowers (Fig 4a) but not enough to statistically distinguish between the seed sets of the red-flowered plants and the yellow-flowered plants. With dragging, but no pollinators the screen cage flowers set an average of $244 \pm 33$ seeds per capsule (Fig. $4 b)$, significantly $(F=23.2770, P<0.0001)$ less than the $450 \pm 24$ of the greenhouse control with dragging, but no pollinators (Fig. 4a).

Testing whether the architecture of the flower, specifically, the nearness of the anthers to the stigma lobes, might be another means of reproductive assurance revealed that it could. In a large experimental population (Fig. 5) in my main pollinator-free greenhouse in which dragging was blocked 196 red flowers set an average of $142 \pm 19$ seeds per capsule. The 179 yellow flowers tested set very significantly $(F=42.7308, \quad P<0.0001)$ fewer seeds-an average of only $10 \pm 4$ seeds per capsule.

Testing for parthenogenesis yielded no convincing evidence of its presence (Table 1). In the total of 784 flowers tested in successive years 689 failed to set seeds at all. Of those that did, there was great variation from 1 or 2 to a few of 1500 or more. There was no consistent production of
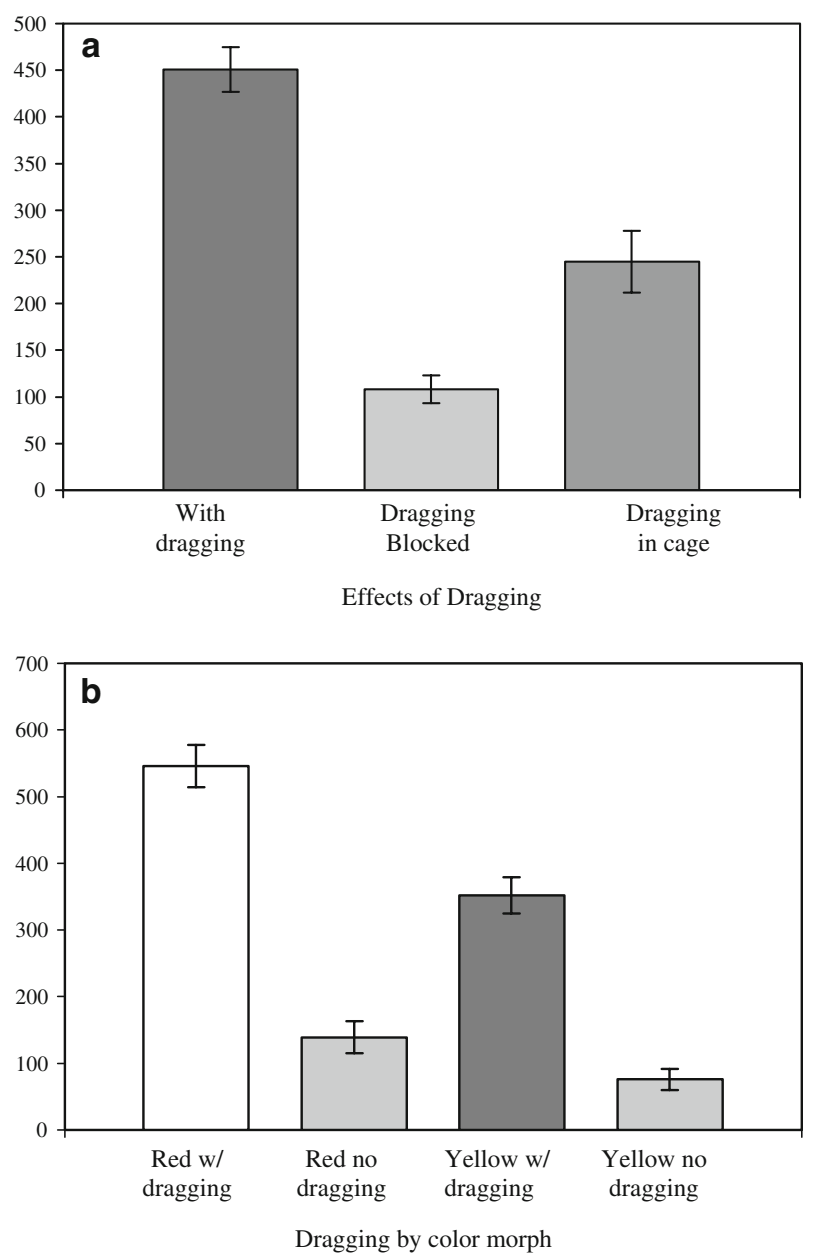

Fig. 4 (a) Dragging experiments in the pollinator-free greenhouse and in a pollinator-free screen cage in the experimental garden-overall mean seed sets per capsule, mixed populations of red and yellow color morphs. (1) With dragging, $450 \pm 24, n=276$. (2) With dragging blocked, $108 \pm 15, n=276$. (3) With dragging in pollinator-free screen cage in the experimental garden. $244 \pm 33, n=111$. The error bars equal \pm one standard error. (b) Dragging experiments in the pollinator-free greenhouse-mean seed sets per capsule of red color morphs and yellow color morphs. (1) Red flowers, with dragging, $546 \pm 37, n=140$. (2) Red flowers, with dragging blocked, $139 \pm 24$, $n=142$. (3) Yellow flowers, with dragging, $352 \pm 27, n=136$. (4) Yellow flowers, with dragging blocked, $76 \pm 16, n=134$. The error bars equal \pm one standard error

seeds in the emasculated flowers even at low levels. Checking for cleistogamy revealed that all the flowers opened before anthesis. There was no opportunity for fertilization to occur in unopened buds. Observing the flowers for stigmatic curling revealed that the two stigma lobes normally were gently recurved at all stages from bud opening to senescence (Fig. 1). They did not undergo further curling, e.g., towards the anthers in either the red or yellow flowers as they aged.

Testing for wind pollination revealed that wind was not a means of reproductive assurance. Checking for pollination due only to wind borne pollen from other flowers of that plant 


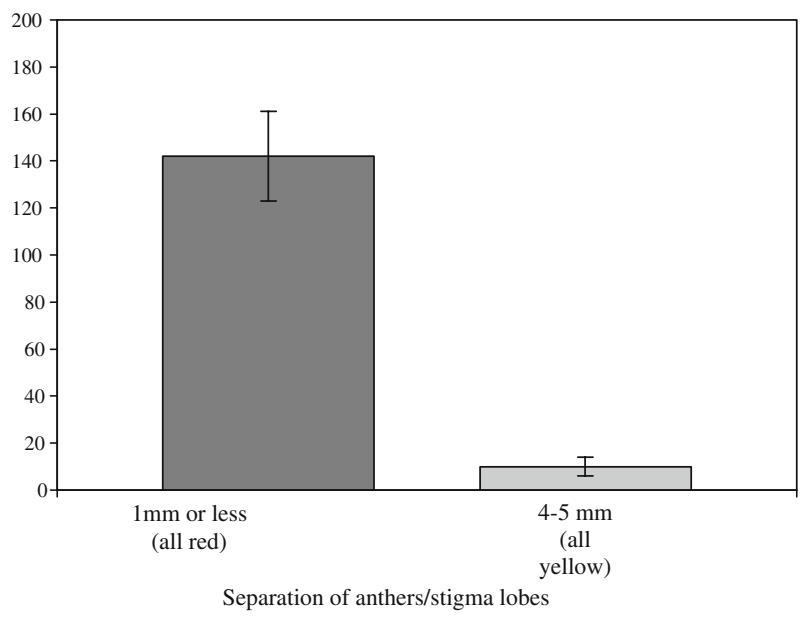

Fig. 5 Architecture of the flower, specifically, nearness of the anthers to the stigma lobes experiments. Mean seed sets with no pollinators, no dragging, and no wind. (1) Red flowers, $1 \mathrm{~mm}$ or less separation of anthers from stigma lobes. Mean seed set per capsule, $142 \pm 19$, $n=196$. (2) Yellow flowers, 4-5 $\mathrm{mm}$ or more separation of anthers from stigma lobes. Mean seed set per capsule, $10 \pm 4, n=179$. The error bars equal \pm one standard error

or its population in the absence of dragging and with no pollinators revealed that in red flowers there was an average seed set of $79 \pm 23$ (Fig. 6a) seeds per capsule with wind (Fig. 6a) and a not significantly $(F=0.2054, P=0.6512)$ different, somewhat higher average of $100 \pm 34$ seeds per capsule without wind (Fig. 6a). The yellow flowers produced an average seed set of $16 \pm 8$ seeds per capsule with wind and a not significantly $(F=0.6621, P=0.4162)$ different $9 \pm 3$ seeds per capsule without wind. Checking for wind-induced self-pollination in the absence of dragging and with no pollinators revealed that the red flowers set an average of $30 \pm 11$ (Fig. 6b) seeds per capsule with wind which is not significantly $(F=0.8615, P=0.3550)$ different from the average $16 \pm 7$ seeds per capsule of the red flowers with no wind (Fig. 6b). With wind the yellow flowers set an average $0.15 \pm 0.10$ seeds per capsule which is not significantly $(F=0.3506, P=0.5551)$ different from the $0.09 \pm 0.04$ of the yellow flowers with no wind, (Fig. 6b).

Table 1 Parthenogenesis experiments

\begin{tabular}{llll}
\hline Year tested & $\begin{array}{l}\text { Number } \\
\text { of flowers }\end{array}$ & $\begin{array}{l}\text { Number set } \\
\text { zero seeds }\end{array}$ & $\begin{array}{l}\text { Percent set } \\
\text { zero seeds }(\%)\end{array}$ \\
\hline 1996 & 176 & 150 & 85 \\
2000 & 134 & 130 & 97 \\
2002 & 108 & 103 & 95 \\
2003 & 366 & 306 & 84 \\
Total & 784 & 689 & 88 \\
\hline
\end{tabular}

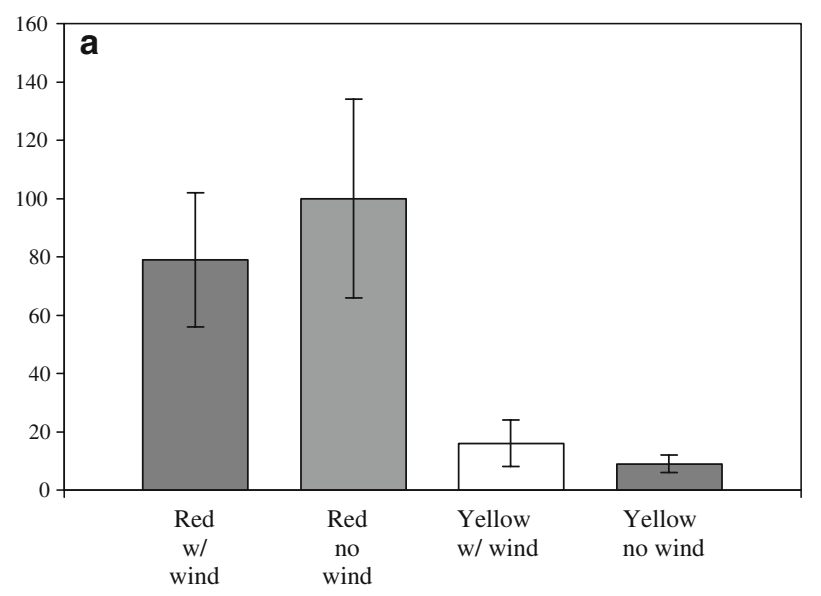

Wind borne pollen from other flowers

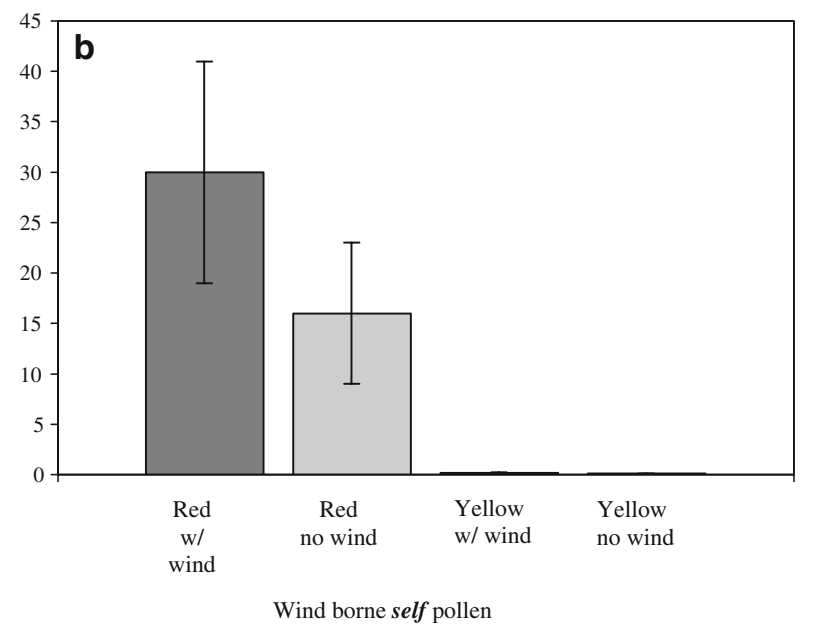

Fig. 6 (a) Wind-borne pollen (from other flowers) experiments-with wind versus no wind - mean seed sets per capsule. (1) Red flowers, with wind, $79 \pm 23, n=58$. (2) Red flowers, no wind, $100 \pm 34, n=60$. (3) Yellow flowers, with wind, $16 \pm 8, n=110$. (4) Yellow flowers, no wind, $9 \pm 3, n=108$. The error bars equal \pm one standard error. (b) Wind borne self pollen experiments- with wind versus no wind-mean seed sets per capsule. (1) Red flowers, with wind, $30 \pm 11, n=80$. (2) Red flowers, no wind, $16 \pm 7, n=51$. (3) Yellow flowers, with wind, $0.15 \pm 0.1, n=46$. (4) Yellow flowers, no wind, $0.09 \pm 0.04, n=56$. The error bars equal \pm one standard error

\section{Discussion}

The experiments and observations showed that $M$. verbenaceus is self-fertile and sets abundant seeds in the absence of pollinators, almost as many as when carefully handpollinated. This seed set without pollinators appears to be achieved by means of two reproductive assurance mechanisms - dragging and nearness of the anthers to the stigma lobes.

The biologic basis for dragging was firmly established with the demonstration that the pollen and ovules in senescing flowers were not only still viable and functional, but produced ample seeds for fertility. The 3- to 4-day old 
pollen and ovules of senescing flowers were able to produce approximately one-third the normal seed sets of the young pollen $\mathrm{x}$ young ovule hand-pollinated controls. This is in line with the findings of Dudash and Ritland (1991) that the last 2-3 days of sequential pollinations during the 3-4 day life of Mimulus guttatus flowers accounted for an average of $48 \%$ of the flowers' seed sets.

Not only was the dragging mechanism of reproductive assurance biologically possible but it appeared to be highly effective in my pollinator-free greenhouse. However, the results of Dudash and Ritland (1991) and LeClere-Potuin and Ritland (1994) showed zero effect of dragging in $M$. guttatus in natural populations as did Mitchell et al. (2004) for Mimulus ringens.

Would dragging be effective in natural populations of M. verbenaceus? The population in the pollinator-free screen cage in the experimental garden was the closest feasible approach to a natural desert seep or spring population that I could manage. Its $244 \pm 33$ average seed set is significantly $(F=23.1397, P<0.0001)$ less than the corresponding greenhouse dragging value of $450 \pm 24$ seeds per capsule (Fig. 4a). It seems fair to conclude that dragging in $M$. verbenaceus is significantly less effective outdoors as in M. guttatus and M. ringens, but that it is far from zero. Perhaps this reflects the possibility that selection for reproductive assurance would be much stronger for the typically small, very much isolated desert populations of $M$. verbenaceus than for the often large, less isolated, more mesic populations of $M$. guttatus and M. ringens.

The architecture of the flower, specifically the nearness of the anthers to the stigma lobes, proved to be a second means of reproductive assurance. When dragging was blocked, and in the absence of pollinators, the red flowers set a substantial number of seeds, an average $142 \pm 19$ seeds per capsule. Apparently their hairy anthers with their load of pollen could easily brush the stigma lobes in the course of normal flower and plant movements. In contrast, the yellow flowers in which the anthers are further from the stigma lobes set very few seeds, an average of $10 \pm 4$ seeds per capsule. The difference of ca. 130 seeds per capsule between the average seed sets of the yellow and red flowers is a measure of the effectiveness in the red flowers of this second reproductive assurance mechanism, the nearness of the anthers to the stigma lobes. Also importantly, it nicely explains the tendency for higher seed sets of the red flowers than the yellow flowers in the earlier experiments. The action of this second means of reproductive assurance in the red flowers, but effectively not in the yellow flowers, also may explain the relative abundance of the red-flowered plants and the relative scarcity of the yellow-flowered plants in the specialized desert habitats of M. verbenaceus (Grant 1924). In fact, why are there any yellow-flowered plants at all?
Would selfing-the corner stone of both reproductive assurance methods-explain the persistence of the yellow morph? Selfing yellow, as expected for a homozygous recessive genotype would breed true as would it's closely linked gene(s) for clear separation of the anthers from the stigma lobes. However, the lower fecundity of the yellow morph than the red morph would lead almost certainly to it's gradual loss from the population. The homozygous dominant red morph would breed true for red color and it's closely linked gene(s) for close proximity of the anthers to the stigma lobes. The heterozygous red morph would segregate for yellow with clear anther separation from the stigma lobes and red with anthers in close proximity to the stigma lobes. In time, the yellow morph would be expected to be lost as above. Ultimately, the probable explanation for the persistence of the yellow morph is occasional mutation as is commonly assumed for albinos.

The flowers of the parthenogenesis experiments failed overwhelmingly to set seeds but some did set a few seeds and a few set abundant seeds. Was this successful parthenogenesis in a few cases, or was it experimental error? It appears to be experimental error because the resulting populations did not show the striking uniformity normally observed in apomietic populations (Koltunow et al. 2001, Hiesey and Nobs 1982-I observed and helped score their Poa plants). However, no allozyme tests of parents and progeny were run to verify this conclusion. The experimental error almost surely took the form of inadvertently not noticing that anthesis had occurred before emasculating these flowers.

Cleistogamy, as observed in Oxalis (Redbo-Torstensson and Berg 1995), Viola (Culley 2002), and the $n=13$ variety of Mimulus nasutus Greene, section Simiolus (personal observation), was not observed in M. verbenaceus. Stigmatic curling, an important means of reproductive assurance in M. guttatus (Dole 1992), was not observed in M. verbenaceus.

Counter-intuitively, wind was not found to be a means of reproductive assurance. The seed sets achieved with wind and without wind were not significantly different. However, from whence did the observed seed sets come? There were no pollinators and dragging was blocked. The effect of nearness of the anthers to the stigma lobes was not blocked and appears to account for the seed sets. In confirmation, as would be predicted, the red flowers set many times more seeds that the yellow flowers.

Comparing all the red floral morph tests with the yellow floral morph tests was revealing. In most cases, flower color made no difference per se. In the case where it apparently made a striking difference- the nearness of the anthers to the stigma lobes-it was not the color difference itself, but the difference in the closely linked quantitative genes for separation of the anthers from the stigma lobes 
that mattered. Due to that close linkage the result of the comparison was that the second means of reproductive assurance functioned in the red flowers but effectively not in the yellow flowers. Flower color serves as a highly visible marker for the closely linked underlying characteristic of nearness of anthers to stigma lobes.

The seed sets varied considerably from experiment to experiment probably due to variation in the amounts of pollen applied, variation in inbreeding depression as in $M$. guttatus (unpublished data), and slight variations in the environment from one experiment to another. Nevertheless, the seed sets of the combination of the dragging and the nearness of anthers to stigma lobes reproductive assurance mechanisms are ample to account for the observed seed sets in the absence of pollinators.

In conclusion, in the absence of pollinators $M$. verbenaceus sets abundant seeds, typically averaging from 200 to 800 seeds per capsule. Two reproductive assurance mechanisms have evolved to achieve this-first and principally, dragging, and secondarily, the nearness of the anthers to the stigma lobes. The first mechanism, dragging, operates in both red and yellow flowers. It explains, in large measure, the ability of $M$. verbenaceus to survive in remote desert habitats with few, if any, pollinators. The second mechanism operates in the red flowers but scarcely at all in the yellow flowers which may well explain the relative abundance of red flowered plants and scarcity of yellow flowered plants in nature, as well as the tendency for higher seed sets in the red flowers than the yellow flowers. Parthenogenesis appears not to play a role, nor does cleistogamy, nor does stigmatic curling, nor does wind pollination. The dragging reproductive assurance mechanism of self-pollination appears to account for most (ca. 75\% or more) of the seeds set in the absence of pollinators and the nearness of the anthers to the stigma lobes for the rest, almost entirely in the red flowers and hardly at all in the yellow flowers. The proportions vary under even slightly different conditions. The two mechanisms of reproductive assurance appear to be much stronger and more effective in $M$. verbenaceus than do the mechanisms of reproductive assurance in M. guttatus (Dole 1990, 1992). They appear to have enabled M. verbenaceus to invade, compete and survive in the special habitats of remote, isolated desert seeps and springs where M. guttatus does not seem to occur (Abbey 1971 and Vickery, personal observation). In turn, the strong selective pressures of those environments must act to hone down both mechanisms of reproductive assurance in $M$. verbenaceus.

Acknowledgments The author thanks S. Sutherland who kindly collected transplants of the yellow-flowered morph and M. A. Keebler who, with a rock-climbing friend, kindly collected the seeds of the red-flowered morph, both morphs of the Vassey's Paradise population, M. Tempest-Lambert for her drawings of the M. verbenaceus flowers, J. Peterson for his help with the statistics, E. King for measuring the pollen, and B. McKean and K. Zundel for all their typing and much help with the computer. He also wishes to thank $\mathrm{N}$. Waser for his helpful criticisms and suggestions. In addition, he also thanks the University of Utah Research Committee for financial help.

Open Access This article is distributed under the terms of the Creative Commons Attribution Noncommercial License which permits any noncommercial use, distribution, and reproduction in any medium, provided the original author(s) and source are credited.

\section{Appendix 1}

\section{Vouchers of Mimulus verbenaceus Greene}

The vouchers are on deposit in the Garrett Herbarium (UT) of the University of Utah, Salt Lake City, Utah 84112, USA.

1. Garrett Herbarium number UT 120,140 (Vickery culture number 14,089), the yellow-flowered morph grown from transplants collected by S. Sutherland April 20, 1986 from a population growing among talus rocks below its "hanging garden" seep on the wall of Vassey's Paradise, Grand Canyon, Arizona, USA.

2. Garrett Herbarium number UT125,666 (Vickery culture number 14,088), the red-flowered morph grown from seeds collected by MA Kebler September 5, 1989 from a population growing in a "hanging garden" seep high on the wall of Vassey's Paradise, Grand Canyon, Arizona, USA.

\section{References}

Abbey, E. (1971). Desert Solitaire. New York, NY, USA: Ballantine Books, Inc.

Arizona Coconino County. (1985). North Canyon Point Quadrangle [topographic map]. Denver, Colorado, USA. United States Department of the Interior, Geological Survey.

Armbruster, W. S., Mulder, C. P. H., Baldwin, B. G., Kalisz, S., Wessa, B., \& Nute, H. (2002). Comparative analysis of late floral development and mating-system evolution in tribe Collinsieae (Scrophulariaccae s.1.). American Journal of Botany, 89(1), 3749. doi:10.3732/ajb.89.1.37.

Baker, H.G. (1959). Reproductive methods as factors in speciation in flowering plants. Cold Spring Harbor Symposia on Quantitive Biology (Vol. 24, pp. 177-191). Long Island Biological Association, Biological Laboratory, Long Island, NY, USA: Cold Spring Harbor.

Beardsley, P. M., \& Olmstead, R. G. (2002). Redefining Phrymaceae: The placement of Mimulus, tribe Mimuleae, and Phryma. American Journal of Botany, 89(7), 1093-1102. doi:10.3732/ ajb.89.7.1093.

Beardsley, P. M., Yen, A., \& Olmstead, R. G. (2003). AFLP phylogeny of Mimulus section Erythranthe and the evolution of hummingbird pollination. Evolution; International Journal of Organic Evolution, 57(6), 1397-1440.

Culley, T. M. (2002). Reproductive biology and delayed selfing in Viola pubescens (Violaceae), an understory herb with 
chasmogamous and cleistogamous flowers. International Journal of Plant Sciences, 163(1), 113-122. doi:10.1086/324180.

Dole, J. A. (1990). Role of corolla abscission in delayed selfpollination of Mimulus guttatus (Scrophulariaceae). American Journal of Botany, 77(11), 1505-1507. doi:10.2307/2444762.

Dole, J. A. (1992). Reproductive assurance mechanisms in three taxa of the Mimulus guttatus complex (Scrophulariaceae). American Journal of Botany, 79(6), 650-659. doi:10.2307/2444881.

Dudash, M. R., \& Ritland, K. (1991). Multiple paternity and selffertilization in relation to floral age in Mimulus guttatus (Scrophularioceae). American Journal of Botany, 78(12), 1746-1753. doi:10.2307/2444854.

Erdtman, G. (1969). Handbook of polynology. New York, NY, USA: Hafner Publishing Co.

Etcheverry, A. V. (2001). Role of staminal growth in delayed selfpollination of Crotalaria stipalaria (Fabaceae: Papilionoideae). Beitrage zut Biologie der Pflanzen, 72, 215-228.

Fenster, C. B., \& Martén-Rodríguez, S. (2007). Reproductive assurance and the evolution of pollination specialization. International Journal of Plant Sciences, 168(2), 215-228. doi: $10.1086 / 509647$

Grant, A. L. (1924). A monograph of the genus Mimulus. Annals of the Missouri Botanical Garden, 11, 99-389. doi:10.2307/ 2394024.

Herlihy, C. R., \& Eckert, C. G. (2002). Genetic cost of reproductive assurance in a self-fertilizing plant. Nature, 416(6878), 320-323. doi:10.1038/416320a.

Hiesey, W. M., Nobs, M. A., \& Björkman, O. (1971). Experimental studies on the nature of species. V. Biosystematics, genetics, and physiological ecology of the Erythranthe section of Mimulus. Publication 628. Washington DC, USA: Carnegie Institution of Washington.

Hiesey, W. M., \& Nobs, M. A. (1982). Experimental studies on the nature of species. VI. Interspecific hybrid derivatives between facultatively apiomcetic species of Bluegrasses and their responses to contrasting environments. Publication. 636. Carnegie Institution of Washington. Washington DC, USA.

Judd, W. S., Campbell, G. S., Kellog, E. A., Stevens, P. F., \& Donoghue, M. F. (2008). Plant systematics $-A$ phylogenetic approach (3rd ed.). Sunderland, MA, USA: Sinauer Associates.

Karrenberg, S., Kollman, J., \& Edwards, P. J. (2002). Pollen vectors and inflorescence morphology in four species of Salix. Plant Systematics and Evolution, 235, 181-188. doi:10.1007/s00606002-0231-z.

Koltunow, A., Johnson, S., Tucker, M., Paech, N., Tassie, A., \& Vivian-Smith, A. (2001). Apomixis-A seed by any means? p. 19. In T. Dresselhaus \& L. Colombo (Eds.), 2nd International Apomixis Conference (APO 2001) at Como, Italy, 24-28 April
2001, Springer-Verlag, 166 pp. published online 12 October 2001, http://www.apomixis.de.

LeClere-Potuin, C., \& Ritland, K. (1994). Modes of self-fertilization in Mimulus guttatus (Scrophulariaceae): A field experiment. American Journal of Botany, 81(2), 199-205. doi:10.2307/ 2445634.

Microsoft Excel 98 computer program (1998). Microsoft Corporation, One Microsoft Way, Redmond, WA 98052-6399.

Mitchell, R. J., Karron, J. D., Holmquist, K. G., \& Bell, J. M. (2004). The influence of Mimulus ringens floral display size on pollinator visitation patterns. Functional Ecology, 18, 116-124. doi:10.1111/j.1365-2435.2004.00812.x.

Niklas, K. J. (1985). Wind Pollination-A study in controlled chaos. American Scientist, 73, 462-470.

Palleiro, N., Mandujano, M. C., \& Golubov, J. (2006). Aborted fruits of Opuntia microdasys (Cactaceae): Insurance against reproductive failure. American Journal of Botany, 93(4), 505-511. doi: 10.3732/ajb.93.4.505.

Redbo-Torstensson, P., \& Berg, H. (1995). Seasonal cleistogamy, A conditional strategy to provide reproductive assurance. Acta Botanica Neerlandica, 44(3), 247-256.

Schemske, D. W., \& Bradshaw, H. D., Jr. (1999). Pollinator preference and the evolution of floral traits in monkeyflowers (Mimulus). Proceedings of the National Academy of Sciences of the United States of America, 96(21), 11910-11915. doi: 10.1073/pnas.96.21.11910.

Squilace, A. E., \& Goddard, R. E. (1982). Selfing in clonal seed orchards of Slash Pine, Pinus elliottii. Forest Science, 28(1), 7178.

Steven, J. C., \& Waller, D. M. (2004). Reproductive alternatives to insect pollination in four species of Thalictrum (Ranunculaceae). Plant Species Biology, 19, 73-80. doi:10.1111/j.1442-1984.2004. 00103.x.

Thompson, D. M. (1993). Mimulus. In J. C. Hickman (Ed.), The Jepson manual (pp. 1037-1047). Berkeley, CA, USA: University of California Press.

Vickery, R. K., Jr. (1978). Case studies in the evolution of species complexes in Mimulus. Evolutionary Biology, 11, 405-507.

Vickery, R. K., Jr., \& Wullstein, B. M. (1987). Comparison of six approaches to the classification of Mimulus section Erythranthe (Scrophulariaceae). Systematic Botany, 12(3), 339-364. doi: $10.2307 / 2419258$.

Vickery, R. K., Jr., \& Miller, M. (2007). Plantaginaceae (genus Mimulus). In K. Marhold \& G. N. Feliner (Eds.), 1APT/10 PB chromosome data 4. Taxon, 56(4), 1269.

Weather Bureau. (1988-1997). Climatological Data-Arizona Section. United States Department of Commerce. Vols. 92-101. Ashville, NC, USA. 